\title{
Deciphering the Quality of Life among Tuberculosis Patients under RNTCP in Karnataka, India
}

\author{
Jannatbi L. Iti1 ${ }^{*}$, Roshan Mudaraddi ${ }^{2}$, Sharath Burugina Nagaraja ${ }^{3}$, Suresh Shastri ${ }^{4}$ \\ ${ }^{1}$ Department of Community Medicine, Gadag Institute of Medical Sciences, Gadag, India \\ ${ }^{2} \mathrm{SN}$ Medical College, Bagalkot, India \\ ${ }^{3}$ ESIC Medical College and PGIMSR, Bengaluru, India \\ ${ }^{4}$ RNTCP State TB Cell, Bengaluru, India \\ Email: *drjannatbi@gmail.com
}

How to cite this paper: Iti, J.L., Mudaraddi, R., Nagaraja, S.B. and Shastri, S. (2019) Deciphering the Quality of Life among Tuberculosis Patients under RNTCP in Karnataka, India. Journal of Tuberculosis Research, 7, 45-55.

https://doi.org/10.4236/jtr.2019.72005

Received: March 18, 2019

Accepted: April 25, 2019

Published: April 28, 2019

Copyright $\odot 2019$ by author(s) and Scientific Research Publishing Inc. This work is licensed under the Creative Commons Attribution International License (CC BY 4.0).

http://creativecommons.org/licenses/by/4.0/

\begin{abstract}
Background: The Tuberculosis (TB) disease has immense impact on physical, psychological, economic and social well-being of an individual. It is desired that the patient with any kind of TB disease should lead a respectable and happier life during their course of TB treatment. Currently, the quality of life (QOL) is an important indicator to assess the well-being of a person and there is paucity of such information among TB patients. Hence, we conducted to assess and compare the QOL of Revised National TB Control Programme registered Drug sensitive TB patients, Drug resistant TB patients and general population of Gadag district in Karnataka, India. Methods: A crosssectional study was conducted in Gadag district, Karnataka from March 2017 through March 2018 among drug sensitive, drug resistant TB patients and general population. A Non-probability purposive sampling was adopted to select the samples that were matched for age, gender and ward. The select patients were administered WHO QOL-BREF questionnaire by trained personnel. Data were analyzed using SPSS version 12 analysis software. Results: The scores obtained for the four domains of QOL were (a) physical health: $69.62+$ 18.29 (b) Psychological: $66.96+18.62$ (c) Environment: $60.99+15.05$ and (d) Social relationships: $53.5+19.93$. Conclusions: The drug resistant TB patients have poor QOL when compared to drug sensitive and general population.
\end{abstract}

\section{Keywords}

Quality of Life, Operational Research, WHO QOL-BREF, RNTCP 


\section{Introduction}

Globally, tuberculosis (TB) remains as a major public health problem. As per the WHO Global report 2017, India accounts for nearly $25 \%$ of global burden with approximately 2.8 million cases [1]. The proportion of Multi drug resistant tuberculosis (MDR-TB) among new and previously treated tuberculosis cases is found to be $2.84 \%$ and $11.6 \%$ respectively. The disease apart from causing morbidity also takes a toll on the physical, psychological, economic and social wellbeing of a person. This could be due to combination of factors related to stigma, economic unproductivity, prolonged duration of treatment, frequent hospital visits, pill burden and adverse drug reactions [2]. The situation is grim among those suffering from drug resistant TB (DR-TB). The impact of the disease is seen not only with the infected person but also on their family [3]. For the comprehensive assessment of patient's health status, it is essential to consider the overall effect of tuberculosis on health and patient's perception of well-being [3]. The increasingly mechanistic model of medicine, concerned only with the eradication of disease and symptoms, reinforces the need for the introduction of a humanistic element into health care [4].

The quality of life (QOL) indicator is an important measure to assess the well being of a person. The improved QOL of a person determines the well being of his physical, psychological, social and environmental health. A patient with good QOL is known to have good compliance to treatment. It serves as an indirect measure to assess the Tuberculosis patient's compliance to treatment during and before initiation of treatment [5]. The evaluation of health-related QOL of tuberculosis patients gives the programme an in-sight into patients' sufferings and the disease influence on their daily routine life. A better understanding of the tuberculosis patients' experiences can help the programme to devise strategies to improve the treatment service delivery and minimize the affecting risk factors [6].

The Revised National TB Control Programme (RNTCP) has no information on the QOL of TB patients initiated on treatment and there is a dire need to evaluate among the drug sensitive and drug resistant tuberculosis patients. We conducted this study among the RNTCP registered drug sensitive, drug resistant patients and general population to assess and compare the QOL using WHO standardized questionnaire.

\section{Methodology}

\subsection{Study Area, Design and Source of Data}

A cross-sectional study was conducted in Gadag district, Karnataka, India from March 2017 through March 2018. The district is located in northern part of Karnataka and has a population of $\sim 10$ million in 4656 square kilometre of geographical area, density of 209 per square kilometre. The total working population in the district comprises of cultivators (1.5 million), agricultural labourers (1.4 million), household industry (1.5 million) and other workers. The district 
has a literacy rate of $66.1 \%$, and a sex ratio of 978 females for every 1000 males. Every year nearly 1000 patients were initiated on RNTCP treatment [7] [8]. The health care services in the districts are mainly provided by the public and the private health facilities.

For the purpose of the study, a line list of drug sensitive and drug resistant TB patients registered under RNTCP in Gadag district during July 2015 to June 2017 were made. Drug sensitive TB cases and general population were matched for age, gender and locality wise with the DR-TB patients, who were willing to participate in the study were included.

A non-probability purposive sampling was used to select 31 drug sensitive tuberculosis patients and 41 general population, who were matched for age, gender and locality wise with the DR-TB patients. If new case of DS-TB patients were not available in same age group as the DR-TB patients, then subjects with age + 5 years were included in the study.

A house to house visits by Principal Investigator (PI) and Co-PI along the RNTCP programme staff were made to administer the questionnaire. After obtaining informed written consent, the study subjects were interviewed personally using pre-designed and pretested WHOQOL-BREF questionnaire. The interview was conducted using local language (kannada) at a place and time convenient to the patient [9]. Each interview was lasted for about 50 - 60 minutes. Similar, time management was ensured for all study subjects to avoid the interviewer bias. At the end of the interview, the study participants were educated regarding the modes of TB transmission, treatment compliance, nutrition and cough etiquette.

\subsection{Procedure and Instruments}

The WHOQOL-BREF is a 26 -item instrument consisting of four domains: physical health (7 items), psychological health (6 items), social relationships (3 items), and environmental health (8 items) (Box 1); it also contains QOL and general health items. Each individual item of the WHOQOL-BREF is scored from 1 to 5 on a response scale, which is stipulated as a five-point ordinal scale. The scores are then transformed linearly to a $0-100$-scale. The physical health domain includes items on mobility, daily activities, functional capacity, energy, pain, and sleep. The psychological domain measures include self-image, negative thoughts, positive attitudes, self-esteem, mentality, learning ability, memory concentration, religion, and the mental status. The social relationships domain contains questions on personal relationships, social support, and sex life. The environmental health domain covers issues related to financial resources, safety, health and social services, living physical environment, opportunities to acquire new skills and knowledge, recreation, general environment (noise, air pollution, etc.), and transportation [9].

WHO Quality of Life-BREF was developed for cross cultural usage and estimates the domains of Physical health, Psychological, Social relationships and Environment which assess the quality of life. For each domain the minimum score is zero and maximum score accorded is 100 . The Kannada version of 
Box 1. WHO-QOL BREFF Domains and their areas [8].

\begin{tabular}{|c|c|c|}
\hline S. No. & Domains & Items \\
\hline \multirow[t]{7}{*}{1} & Physical & 1. Activities of daily living \\
\hline & & 2. Dependence on medicinal substances and medical aids \\
\hline & & 3. Energy and fatigue \\
\hline & & 4. Mobility \\
\hline & & 5. Pain and discomfort \\
\hline & & 6. Sleep and rest \\
\hline & & 7. Work Capacity \\
\hline \multirow[t]{6}{*}{2} & Psychological & 1. Bodily image and appearance \\
\hline & & 2. Negative feelings \\
\hline & & 3. Positive feelings \\
\hline & & 4. Self-esteem \\
\hline & & 5. Spirituality/Religion/Personal beliefs \\
\hline & & 6. Thinking, learning, memory and concentration \\
\hline \multirow[t]{3}{*}{3} & Social & 1. Personal relationships \\
\hline & & 2. Social support \\
\hline & & 3. Sexual activity \\
\hline \multirow[t]{8}{*}{4} & Environmental & 1. Financial resources \\
\hline & & 2. Freedom, physical safety and security \\
\hline & & 3. Health and social care: accessibility and quality \\
\hline & & 4. Home environment \\
\hline & & 5. Opportunities for acquiring new information and skills \\
\hline & & 6. Participation in and opportunities for recreation/leisure activities \\
\hline & & 7. Physical environment (pollution/noise/traffic/climate) \\
\hline & & 8. Transport \\
\hline
\end{tabular}

WHOQOL-BREF was validated and administered to the study subjects [9].

WHOQOL-BREF has two items that are examined separately: question one enquires about an individual's overall perception of quality of life and questions two on perception of their health (Box 1). The four domain scores denote an individual's perception of quality of life in each particular domain. Domain scores were scaled in a positive direction which presumes that higher scores denote higher quality of life. The mean score of items within each domain was used to calculate the domain score. Mean scores were then multiplied by four in order to make domain scores comparable with the scores used in the WHOQOL-100. By manual calculation each domain scores were converted to transformed scores [9].

Operational Definition for QOL: The quality of life is defined as individuals' perceptions of their position in life in the context of the culture and value systems in which they live and in relation to their goals, expectations, standards and 
concerns [9].

\subsection{Statistical Analysis}

The data variables collected included (a) socio-demographic variables (age, gender, religion, address, marital status, education, occupation, family type, number of children, socio-economic status) (b) tuberculosis history and management variable (Tuberculosis category, previous treatment history, height, weight) and (c) Quality of life (which includes four domains like physical, psychological, social relations, and environment health). Responses collected in the proforma were doubly entered and validated using EpiData v3.1 (Odense Denmark) data entry software. Descriptive statistics were analysed for frequency, proportions, chi-square test, mean and standard deviation. Two-sided 'p' value of $<0.05$ was considered as statistically significant. Comparisons of quality of life of general population, drug sensitive and drug resistant tuberculosis patients and association between socio-demographic factors and quality of life were calculated using SPSS statistical software (version 12).

\subsection{Ethical Review}

The Institutional Ethics Committee approval was obtained from the Gadag Institute of Medical Sciences, Gadag. Necessary permissions were obtained from the District Health and TB officers of Gadag district. Informed written consent in local Kannada language was taken from all the study participants for voluntary participation. If the study participant was illiterate, then the details of the study were explained in presence of a witness and left thumb impression of the participants and signature of the witness was taken on the consent form. If the patient is in paediatric age group consent was obtained from the parents.

\section{Results}

Of the 100 subjects included in the study; 31 had drug sensitive TB, 28 had drug resistant TB and 41 were from general population without any TB. The mean age of the participants were 35 years; majority were females (56\%), married (72\%), skilled workers ( $42 \%$ ) by occupation, living in a rural area $(75 \%)$, nuclear family (71\%) and of socio-economic status IV (32\%) according to modified B.G. Prasad classification [10]. Nearly $17 \%$ of subjects had habits of smoking or tobacco usage or alcohol intake. Among the subjects who had TB, nearly $40 \%$ of drug-sensitive $\mathrm{TB}$ and $65 \%$ of drug resistant $\mathrm{TB}$ patients were in the continuation phase of their TB treatment (Table 1).

The domain of quality of life for all the subjects in the study population were physical health (mean 70), psychological (mean 67), environment (mean 61) and social relationships (mean 53).

The range of domain scores among study groups were $68-84$ for general population without TB, 47 - 64 for drug sensitive TB and 39 - 55 for drug resistant TB (Table 2). 
Table 1. Distribution and socio-demographic profile of study subjects (drug sensitive TB, drug resistant $\mathrm{TB}$ and general population without $\mathrm{TB})(\mathrm{N}=100)$.

\begin{tabular}{|c|c|c|c|c|}
\hline Variables & Total subjects & $\begin{array}{c}\text { DS-TB } \\
(\mathrm{n}=31)\end{array}$ & $\begin{array}{c}\text { DR-TB } \\
(n=28)\end{array}$ & $\begin{array}{l}\text { GP without TB } \\
(n=41)\end{array}$ \\
\hline \multicolumn{5}{|c|}{ Age group (years) } \\
\hline & $<15$ & $0(0 \%)$ & $1(3.5 \%)$ & $1(2.5 \%)$ \\
\hline & $15-24$ & $10(32 \%)$ & $8(29 \%)$ & $6(14.5 \%)$ \\
\hline & $25-34$ & $8(26 \%)$ & $4(14 \%)$ & $12(29 \%)$ \\
\hline & $35-44$ & $8(26 \%)$ & $7(25 \%)$ & $11(27 \%)$ \\
\hline & $45-54$ & $2(6.5 \%)$ & $7(25 \%)$ & $6(14.5 \%)$ \\
\hline & $55-64$ & $3(9.5 \%)$ & $1(3.5 \%)$ & $5(12.5 \%)$ \\
\hline \multicolumn{5}{|l|}{ Sex } \\
\hline & Male & $16(51.5 \%)$ & $14(50 \%)$ & $14(34.1 \%)$ \\
\hline & Female & $15(48.5 \%)$ & $14(50 \%)$ & $27(65.9 \%)$ \\
\hline \multicolumn{5}{|l|}{ Residence } \\
\hline & Urban & $11(35.5 \%)$ & $7(25 \%)$ & $7(17.1 \%)$ \\
\hline & Rural & $20(64.5 \%)$ & $21(75 \%)$ & $34(82.9 \%)$ \\
\hline \multicolumn{5}{|l|}{ Religion } \\
\hline & Hindu & $27(87 \%)$ & $28(100 \%)$ & $38(92.5 \%)$ \\
\hline & Muslim & $4(13 \%)$ & $0(0 \%)$ & $3(7.5 \%)$ \\
\hline \multicolumn{5}{|c|}{ Marital status } \\
\hline & Married & $22(71 \%)$ & $19(68 \%)$ & $31(75.5 \%)$ \\
\hline & Unmarried & $9(29 \%)$ & $8(28.5 \%)$ & $7(17 \%)$ \\
\hline & Widow & $0(0 \%)$ & $1(3.5 \%)$ & $3(7.5 \%)$ \\
\hline \multicolumn{5}{|l|}{ Education } \\
\hline & Illiterate & $6(19.4 \%)$ & $4(14 \%)$ & $4(10 \%)$ \\
\hline & Primary school & $8(25.8 \%)$ & $4(14 \%)$ & $6(14 \%)$ \\
\hline & Secondary school & $2(6.5 \%)$ & $0(0 \%)$ & $7(17 \%)$ \\
\hline & High school & $5(16.1 \%)$ & $10(36 \%)$ & $11(27 \%)$ \\
\hline & Intermediate/diploma & $5(16.1 \%)$ & $8(29 \%)$ & $9(22 \%)$ \\
\hline & Graduate/post-graduate & $4(12.9 \%)$ & $2(7 \%)$ & $4(10 \%)$ \\
\hline & Profession/honours & $1(3.2 \%)$ & $0(0 \%)$ & $0(0 \%)$ \\
\hline \multicolumn{5}{|l|}{ Occupation } \\
\hline & House wife & $6(19.4 \%)$ & $7(25 \%)$ & $10(24.4 \%)$ \\
\hline & Unemployed & $6(19.4 \%)$ & $7(25 \%)$ & $4(9.75 \%)$ \\
\hline & Unskilled & $4(13 \%)$ & $1(3.5 \%)$ & $4(9.75 \%)$ \\
\hline & Semi-skilled & $1(3.2 \%)$ & $1(3.5 \%)$ & $4(9.75 \%)$ \\
\hline & Skilled & $14(45 \%)$ & $11(39.5 \%)$ & $17(41.5 \%)$ \\
\hline & Clerical, shop owner, farmer & $0(0 \%)$ & $1(3.5 \%)$ & $0(0 \%)$ \\
\hline & Semi-professional/professional & $0(0 \%)$ & $0(0 \%)$ & $2(4.85 \%)$ \\
\hline
\end{tabular}




\section{Continued}

\begin{tabular}{llrrr}
\hline Socioeconomic status & & & \\
& I & $0(0 \%)$ & $1(3.5 \%)$ & $5(12 \%)$ \\
II & $11(35.5 \%)$ & $6(21.5 \%)$ & $6(15 \%)$ \\
& III & $7(22.5 \%)$ & $9(32 \%)$ & $7(17 \%)$ \\
& IV & $7(22.5 \%)$ & $7(25 \%)$ & $18(44 \%)$ \\
& V & $6(19.5 \%)$ & $5(18 \%)$ & $5(12 \%)$ \\
Type of family & & & \\
& Nuclear & $21(68 \%)$ & $16(57 \%)$ & $34(83 \%)$ \\
& Joint & $9(29 \%)$ & $12(43 \%)$ & $7(17 \%)$ \\
& Other & $1(3 \%)$ & $0(0 \%)$ & $0(0 \%)$ \\
& & & & \\
& Any habits (Smoking/tobacco/alcohol) & $5(16 \%)$ & $2(7 \%)$ & $10(24.5 \%)$ \\
& No Habits & & & \\
& & $26(84 \%)$ & $26(93 \%)$ & $31(75.5 \%)$ \\
\hline
\end{tabular}

Table 2. Comparison of study groups and their WHOQOL-BREF domain scores shown as mean and standard deviation.

\begin{tabular}{cccccc}
\hline Domains & $\begin{array}{c}\text { General population } \\
(\mathbf{n}=41)\end{array}$ & $\begin{array}{c}\text { Drug sensitive } \\
(\mathbf{n}=\mathbf{3 1})\end{array}$ & $\begin{array}{c}\text { Drug Resistant } \\
(\mathbf{n}=\mathbf{2 8})\end{array}$ & f-ratio & P value \\
\hline Physical health & $83.7 \pm 6.8$ & $64.1 \pm 19.42$ & $55.1 \pm 13.6$ & 40.01 & 0.00001 \\
Psychological & $80.2 \pm 7.6$ & $61.5 \pm 19.8$ & $53.7 \pm 16.3$ & 29.59 & 0.00001 \\
Social relationship & $68 \pm 13.06$ & $47.6 \pm 13.9$ & $38.8 \pm 19.5$ & 32.56 & 0.00001 \\
Environment & $70.2 \pm 9.2$ & $58.1 \pm 9.3$ & $50.8 \pm 19$ & 20.55 & 0.00001 \\
\hline
\end{tabular}

The mean quality of life in all the four domains of drug resistant TB patients was less compared to drug sensitive TB patients, which in turn is less compared to general population. The QOL across all the four domains were compared with the socio-demographic variables and it was found that there were no associations between the study groups.

\section{Discussion}

It is one of the few studies conducted in India to assess the quality of life among TB patients. Our study findings reveals that the quality of life among the diseased is markedly reduced when compared to the general population and more so among drug resistant $\mathrm{TB}$ patients when compared to drug sensitive TB patients.

The key socio-demographic characteristics of our study population were majority of them were females, had completed high school education, skilled workers by occupation and belonged to low socio-economic status these findings were coherent to study done by Abdullateef Gbenga Sule et al. [11]. Nearly 17\% of the subjects were addicted to smoke as well as smokeless tobacco and to alcohol consumption. The Drug resistant tuberculosis patients were found to be af- 
fected with HIV and diabetes as co-morbidities.

The mean quality of life for all the four domains was less among drug resistant TB patients when compared to new tuberculosis cases and similar findings were recorded in a study by Mona Faisal Al-Qahtani et al. [12]. It is quite obvious that the DR-TB patients would have succumbed to the chronic nature of the disease; as it affects the economic productive lives causing morbidity and decreased financial output due to compromised working capacity. It impairs the patient's ability to perform activities of daily life. It affects different aspects of patient lives, including the functional status, psychological wellbeing and position towards their own life, which will directly affect their quality of life [13].

A better understanding of the TB patients' quality of life will provide the programme to devise holistic strategies which not only encompass the treatment regimen, patient support and nutritional support but also includes holistic approach which shall be directed at enhancing the quality of life [3].

The satisfaction with life and feeling of wellbeing can often be affected by the diagnosis of any chronic disease like 'tuberculosis and chronic renal failure [13]. The environmental and psychological domains were found to be most affected in patients with chronic renal failure according to a study done by Suja Abraham et al. [14].

In TB patients, QOL is a complex combination of disease, poverty, stigma, discrimination and lack of treatment, combined with family life, work and social activities [13].

\section{Physical domain:}

The physical health domain assesses the impact of disease on the level of independence, activities of daily living, pain and discomfort and dependence on medicinal substance, lack of energy, sleep and rest, mobility and capacity to work. Contrarily in our study, this domain was the least affected in all study groups which was similar to a study done by Abdullateef Gbenga Sule et al. [11] However, there were contrast findings in studies done by Dhingra VK [15] et al. and Chamla D [16] where the physical health domain was the most affected by tuberculosis. The occurrence of disease-related ailments and treatment-related adverse events were more common in intensive phase than the continuation phase and since majority of study subjects were in continuation phase probably the physical health domain was least affected in our study.

\section{Psychological domain:}

In our study the psychological domain was the second least affected in all groups and it assessed the impact of self-esteem, positive and negative feelings, bodily appearance and spirituality and this finding was similar to a study conducted by Abdullateef Gbenga Sule et al. [11]. The knowledge about the diagnosis of tuberculosis and its treatment implications are associated with emotional instability, demanding help for the sake of psychological adjustment and coping with the disease [13].

\section{Social domain:}

The worst affected domain in all groups in our study was the social relation- 
ships domain, which assessed the social support, personal relationship and sexuality. All these have a greater role and the deprivation of these will lead to social isolation, lack of social support by friends, restricted social and leisure activities and similar observations were made by Raman Sharma et al. [17]. Stigma and social prejudice associated with tuberculosis negatively affect the course of treatment and the quality of life of tuberculosis patients [13].

\section{Environmental domain:}

The environmental health domain assessed the financial resources, physical safety and security, quality of home environment, quality and accessibility to health and social care, transport and opportunities for leisure activities. This domain was second worst affected in our study and these findings were in contrast to the study conducted by Abdullateef Gbenga Sule et al. [11].

Since transmission of TB is directly associated with the patient's living conditions, their homes need to be assessed for inappropriate ventilation and overcrowding, as closed environments facilitate the transmission and the domestic contacts are at the greatest risk of developing the disease [13].

In general, the assessment of all the four domains across the general population was good when compared to diseased population and was found to be statistically significant.

\section{Strength and Limitations}

The quality of life was assessed in the study to determine the domain, which was mostly affected and interventions were required to correct and prevent it. In contrast to many other quality of life instruments such as Short-Form 36 (SF-36), WHOQOL-BREF includes a domain on environment, which was necessary as environment plays a major role in determining health status, mediating disease pathogenesis and limiting or facilitating access to health care. The quality of life of tuberculosis patients were assessed at the patients domicile and it reflects the field reality. The limitation of the study was that only new tuberculosis patients were included among drug sensitive tuberculosis patients and extrapolating the disease findings to re-treatment drug sensitive TB patients should be done in caution.

\section{Conclusion}

The quality of life in all the four domains were sub-optimal among drug resistant tuberculosis patients when compared to drug sensitive tuberculosis patients which in turn was poor compared to the general population. The worst affected domains are environmental health and social relationship domains, which suggest that improvement in ventilation, environment and awareness about TB to reduce social stigma and discrimination is required. The lower quality of life in all four domains in DR-TB patients negatively affects the course of treatment and its outcome, hence evaluation of the QOL is necessary for DR-TB patients. By applying quality of life assessments in health care, attention can be focused 
on the aspect of patients' well-being thereby improving their treatment compliance, enhancing treatment success and can be used as a quality care indicator for the TB treatment program.

\section{Acknowledgements}

The study was undertaken as a part of the "Operational Research for Medical College Faculty under Revised National TB Control Programme (RNTCP)" conducted by RNTCP State Task Force Operational Research Committee, Karnataka with the funding support from The State Tuberculosis Office (Government of Karnataka), Bengaluru. The project and manuscript was developed during the "protocol development" and "scientific paper writing" workshops respectively. We acknowledge the facilitation of the study by our Director, Principal and Head of department, Community Medicine, (Gadag Institute of Medical Sciences, Gadag). We express our heartfelt gratitude to District TB Officer (Gadag) and the RNTCP staff of Gadag district for their unconditional support during the conduct of the study.

\section{Disclaimer}

The authors alone are responsible for the views expressed in this publication and they do not necessarily represent the decisions or policies of the State TB Office (RNTCP), Karnataka or the RNTCP State Task Force Operational Research Committee, Karnataka or World Health Organization (India Country Office).

\section{Conflicts of Interest}

The authors declare no conflicts of interest regarding the publication of this paper.

\section{References}

[1] India Tuberculosis Report 2018, Annual Status Report. https://tbcindia.gov.in/showfile.php?lid=3314

[2] Aggarwal, A.N. (2010) Health Related Quality of Life: A Neglected Aspect of Pulmonary Tuberculosis. Lung India, 27, 1-3. https://doi.org/10.4103/0970-2113.59259

[3] Dhuria, M., Sharma, N. and Ingle, G.K. (2008) Impact of Tuberculosis on the Quality of Life. Indian Journal of Community Medicine, 33, 58-59. https://doi.org/10.4103/0970-0218.39249

[4] Sharma, R., Yadav, R., Sharma, M., Saini, V. and Koushal, V. (2014) Quality of Life of Multi Drug Resistant Tuberculosis Patients:a Study of North India. Acta Medica Iranica, 52, 448-453.

[5] Valencia, S., León, M., Losada, I., Sequera, V.G., Quevedo, M.F. and García-Basteiro, A.L. (2016) How Do We Measure Adherence to Anti Tuberculosis Treatment? EXpert Review of Anti-Infective Therapy, 15, 157-165. https://doi.org/10.1080/14787210.2017.1264270

[6] Dourado, V.Z. (2004) Influence of General Clinical Parameters on the Quality of Life of Chronic Obstructive Pulmonary Disease Patients. The Jornal Brasileiro de Pneumologia, 30, 207-214. 
[7] Gadag District Profile. http://khpkvk.org/image/GADAG\%20DISTRICT\%20PROFILE.pdf

[8] Tuberculosis India (2015) Annual Status Report. https://tbcindia.gov.in/showfile.php?lid=3314

[9] WHOQOL-BREF Introduction, Administration, Scoring and Generic Version of the Assessment. http://www.who.int/mental_health/media/en/76.pdf

[10] Singh, T., Sharma, S. and Nagesh, S. (2017) Socio-Economic Status Scales Updated for 2017. International Journal of Research in Medical Sciences, 5, 3264-3267. https://doi.org/10.18203/2320-6012.ijrms20173029

[11] Sule, A.G., Odeigah, L.O., Alabi, K.M., Issa, B.A., Shittu, R.O., Joseph, A.I., Abiola, O.F. and Natie, B.N. (2014) Quality of Life of Patients with Tuberculosis in a Nigerian Teaching Hospital. Turkish Journal of Family Medicine and Primary Care, 8 , 39-47. https://doi.org/10.5455/tjfmpc.46982

[12] Al-Qahtani, M.F., El Mahalli, A.A., Al Dossary, N., Al Muhaish, A., Al Otaibi, S. and Al Baker, F. (2014) Health-Related Quality of Life of Tuberculosis Patients in the Eastern Province, Saudi Arabia. Journal of Talibah University Medical Sciences, 9, 311-317. http://www.sciencedirect.com/science/article/pii/S165836121400064X https://doi.org/10.1016/j.jtumed.2014.04.005

[13] De Farias, S.N.P., Da Silva Medeiros, C.R., Paz, E.P.A., et al. (2013) Completeness in Caring: Study of Quality of Life in Clients with Tuberculosis. Escola Anna Nery, 17, 749-754. https://doi.org/10.5935/1414-8145.20130020

[14] Abraham, S., Venu, A., Ramachandran, A., Chandran, P.M. and Raman, S. (2012) Assessment of Quality of Life in Patients on Hemodialysis and the Impact of Counseling. Saudi Journal of Kidney Disease and Transplantation, 23, 953-957. https://doi.org/10.4103/1319-2442.100875

[15] Dhingra, V.K. and Rajpal, S. (2005) Health Related Quality of Life (HRQL) Scoring (DR-12 Score) in Tuberculosis: Additional Evaluative Tool under DOTS. The Journal of Communicable Diseases, 37, 261-268.

[16] Chamla, D. (2004) The Assessment of Patients' Health-Related Quality of Life during Tuberculosis Treatment in Wuhan, China. International Journal of Tuberculosis and Lung Disease, 8, 1100-1106.

[17] Sharma, R., Yadav, R., Sharma, M., Saini, V. and Koushal, V. (2014) Quality of Life of Multi Drug Resistant Tuberculosis Patients: A Study of North India. Acta Medica Iranica, 52, 448-453. 